\title{
Additional Papers
}

\section{Alan Tapp}

is Senior Lecturer in Marketing at Bristol Business School. As well as a best-selling textbook, Alan has published over 40 papers in leading journals and international conferences. Alan consultancy and training for organisations as diverse as the NSPCC, the Institute of Direct Marketing, Experian Business Strategies, the Royal Mail and Coventry City Football Club. $\mathrm{He}$ is the focal point of a strategic partnership between Bristol Business School and leading DM agency Harrison Troughton Wunderman. He is the author of Principles of Direct and Database Marketing, Europe's first dedicated text in the area, now in its third edition.

\section{Merlin Stone}

is IBM Professor of Relationship Marketing at Bristol Business School, University of the West of England. He is Business Research Leader with IBM's Business Consulting Services and a director of QCi Ltd, the Database Group, the Halo Works, Digital Data Analysis and NowellStone.

Keywords: loyalty cards, retailing, consortium marketing, database marketing, data analysis, partnership has undertaken research,

\section{Dancing in step - The choreography of loyalty partnerships. Can Nectar succeed where Shell Smart failed?}

\author{
Alan Tapp and Merlin Stone \\ Received (in revised form): 23 March 2004
}

\begin{abstract}
The arrival of Nectar has reignited interest in multi-partner loyalty schemes. Industry experts were invited to comment on the implications of the chequered history of other loyalty programmes for Nectar. There are two central issues: first, the set-up of the scheme to make it attractive to consumers, and secondly, the use of customer data to generate actionable insights for the partners. Nectar can justifiably be pleased with its successful consumer marketing. Its next step, turning data into useful actions, will be a major challenge. Some of the difficulties are highlighted and discussed.
\end{abstract}

\section{Introduction}

Many commentators described loyalty schemes as the 'big idea' of the 1990s. ${ }^{1}$ That early optimism has been replaced by caution as many schemes have closed or been reined back. But the loyalty hand is not yet played through. The recent introduction of Nectar into the UK market has reinvigorated interest in loyalty schemes, and in particular, partnership schemes. Costs to each partner can be dramatically reduced, and the consumer appeal increased, by getting a consortium of partners across a broad range of retailing. So, why are partnership schemes still comparatively rare in the UK? After all, they are common throughout Europe. This paper takes a closer look at partnership loyalty schemes. It concludes that both the risks and possible rewards are greater when in partnership than with solus schemes. The advent of Nectar has set up a fascinating 'battle of the cards'. Both Boots and Tesco are outstanding examples of the success of well-run solus schemes. How will Nectar shape up?

\section{Sources and methods}

Dr Alan Tapp

University of the West of England Frenchay Campus

Coldharbour Lane Bristol BS16 1QY, UK Tel: +44 (0) 1173443439 E-mail: alan.tapp@uwe.ac.uk
The study began by compiling an agenda for comment using academic and practitioner literature. This agenda was sent to a number of experienced senior marketers who consult or work in the area of loyalty schemes, and they were invited to comment. Responses were examined and incorporated into this paper where appropriate. 


\section{The battle of the schemes}

\section{Consumers like it simple, but simple is easy to copy}

\section{Background: The Shell programme - Why did it fail?}

The Shell Smart partnership loyalty scheme started in 1996 with high hopes. Commentators described it as one of the time's leading marketing initiatives. ${ }^{2}$ Shell launched its Smart card with the idea of taking it significantly beyond a mere points scheme that incentivises customers to stay. Shell's card allowed consumers to collect and redeem points with Shell plus its scheme partners, including Avis Rent A Car, British Gas and Hilton Hotels.

By 2001 the scheme has been reined back. What had gone wrong? In the end, though not for the want of trying, Shell could not create a scheme that was attractive to themselves, possible partners and consumers. Shell's experience demonstrates how hard it is to manage partnerships, and how tricky the loyalty points 'market' is.

\section{Early learnings on Nectar}

Since then, the launch of Nectar in 2002 raised loyalty stakes to a new high. Nectar's acquisition marketing has been excellent. When Nectar launched in the UK, it combined two existing loyalty schemes, Sainsbury's Rewards and Barclaycard Profiles. It now boasts BP petrol, Debenhams, Vodafone and Ford among its partners. Several more big names are expected to follow in 2004. By April 2003 the partnership had signed up over 17 million customers spread over 12.5 million households, and issued more than 76 billion points. ${ }^{3}$

\section{Tesco's response}

Tesco responded by signing up more partners for its Clubcard scheme. The 18 million members of Marriott Rewards can now earn Clubcard points on stays at any of Marriott's 2,300 global hotels. The points can be redeemed as Marriott Rewards or Clubcard points or converted to Air Miles. The success of Nectar's marketing suggests that reports of points fatigue, at least in the UK, have been exaggerated. According to Carlson Marketing Group, 92 per cent of consumers are involved in a loyalty scheme. ${ }^{4}$ Of these, 78 per cent carry more than one card.

\section{Marketing is key}

That said, lots of cards and lots of points redemption does not always equate to success, at least from the seller's point of view. There are many possible downsides to loyalty points. Competitors can relatively easily copy simple points incentives. In the 1990s in the fuel sector, one launch was quickly matched by competitors. This resulted in a zero-sum game, in which each vendor had effectively dropped their price to consumers, by the same amount, in an expensive way. Consumers often find schemes boring and the incentives of little interest to them. They cannot absorb the minutiae of multiple schemes, and are turned off the entire process.

Avoiding this requires careful marketing. Nectar's success suggests they have addressed the subtleties well. For instance, more than one contributor to this paper suggested that gender is important. The outstandingly successful Boots scheme attracts mainly women. Nectar consumers are more likely to be women while Shell Smart collectors were 


\section{Perception is reality}

\section{Economies of scale}

more likely to be men. Shopping enjoyment is probably also a factor: high involvement leads to high interest in extras such as loyalty cards. Another issue might be the male inability to cope with fiddly details. . ! Both Air Miles and Boots' experience points to the idea of rewards as 'treats' 'this is for me' - as a big factor in their success. Tesco's scheme, on the other hand, appeals to household economics. Nectar has the flexibility to position itself either way.

One key to the successful marketing of loyalty schemes is the management of price perception. A cynic might say there is some sleight of hand here. Giving 1 per cent back to consumers is neither here nor there. If this is given as a price cut consumers do not notice the difference. The 'trick' with loyalty schemes is to give the impression of apparent value: turning the 1 per cent into something consumers do notice. This is where creative marketing comes in - quarterly statements 'add up' all those 1 per cent transactions and give it away in one burst: $£ 25$ a quarter is much better than $£ 2$ a week. Magazine and high-quality TV advertising that build the scheme into one's brand complete the picture.

Up-front marketing is one thing; data management quite another. The paper will tackle this later. First let us examine the mechanism by which partnership schemes work.

\section{How loyalty partnerships work - Nectar}

Take Nectar as an example. The scheme is run by Loyalty Management UK (LMUK). The concept is that a wide range of non-competing partner brands participate in a joint loyalty programme, under the umbrella of an independent loyalty brand. It is based on a successful Canadian loyalty programme, and of course earlier experience of the founder with Air Miles. It has an appealing customer proposition for customers who love to accumulate promotional currency - earn points quicker. Because there are so many more outlets from which to earn points, collectors can accrue enough to redeem on what they choose much faster than if they collect with just one brand. Because they can get points from so many sources, they can save for higher-value rewards. The more partners there are, the greater the attraction for customers, which means more of them sign up, making the scheme more attractive to partners. The larger the scheme, the easier it is to cover its fixed costs. LMUK controls the data captured by the scheme and carries out much of the marketing activity. The segmentation opportunities become clearer when you consider that LMUK sent out 75,000 different versions of their account summary, tailored to take account of the shopping behaviour of consumers.

\section{What is in it for everyone?}

For the scheme to work, in the long term it has to be win-win-win for all the players: consumers, LMUK and the partners.

\section{Consumers}

The customer gains through getting 'something for nothing'. They would have bought the groceries anyway, and they get points as well. In a partner scheme, customers can collect points more quickly and regularly 
compared to single schemes, in particular through their store shopping, credit card, mobile phone and petrol. Collectors in the Nectar scheme can redeem for general rewards that include flying miles, and they need to carry fewer cards. There are plenty of redemption partners to choose from and plenty of collection partners to collect from. This is one of the successes of partnership schemes - points volumes are easy to accumulate. On the other hand they need to be because each point arguably is not terribly valuable: you need to buy 500 litres of petrol to get enough free points for a McDonald's meal. This last point is subjective, of course: some consumers may regard this as reasonable value. Most likely, fairly complex schemes like this tend to attract those kinds of people who can be bothered to work through the detail, and engage with the idea of collecting points here, there and everywhere. This is true of all points schemes, and is a reality of the sector.

\section{LMUK}

LMUK wins by pocketing the difference between money they pay to an organisation at which a customer redeems - redemption partners - and the money they are paid when another partner - collect partners issues points.

\section{Collect partners}

\section{Hidden complexities}

Now to the partners - take a deep breath. It is not simply the case that a customer buys at one partner and redeems at any of the others. In fact there is little cross-over between collecting and redeeming points, except at Sainsbury's and Argos. When they initially signed up, customers may have been somewhat surprised that, for example, a Vodafone customer earning Nectar points cannot redeem those points for a lower phone bill. Similarly a BP customer can redeem their points at Sainsbury's, but not at BP garages. Once they get used to the scheme, consumers may be happy enough with the idea of collecting points at $\mathrm{X}$ and getting their rewards at $\mathrm{Y}$.

Let us take the example of BP and examine it in slightly more detail. BP gives its customers Nectar points which they can collect for rewards elsewhere. BP has to pay LMUK for these points. In return, BP wants to get the following:

- BP customers to spend more of their share of fuel wallet at BP than they would otherwise have done

- Nectar customers who are not currently BP customers to switch to BP, either through basic cross-sell activity by BP using the Nectar database, or more simply because competitor customers switch to BP because they are attracted to Nectar points and switch of their own accord

- data-driven insights into BP customers that they would not get from conventional market research, which lead to more powerful business and marketing decision making.

$\mathrm{BP}$ also risks losing out. It may lose out through rewarding customers for what they were doing anyway. In the case of a partner scheme like this 


\section{Schemes don't come cheap}

one, the problem is enhanced when the reward is redeemed elsewhere (as opposed to with themselves in a solus scheme). Of course, some decisions (eg grocery shopping) are driven mainly by location, but even here customers may have two options, as catchment areas vary by time of day and day of week, and also some shopping is from work, on the way home rather than from home. In general, the more real choice or discretion the customer has, the more influential the loyalty scheme.

\section{Redemption partners}

Some firms deliver the rewards, for which they are rewarded by LMUK. The underlying economics here in some instances play out much as they do for Air Miles - yield management. Redemption partners may be airlines, holiday firms or places to eat out that can sell excess volume cheaply. In other instances a different business case applies. For example McDonald's is a redemption partner. For 500 points you can enjoy a 'medium extra value meal'. McDonald's presumably charges LMUK for these points, and may also gain through encouraging repeat shopping at their restaurants that they would not otherwise get. Only Sainsbury's and Argos are both collect partners and redemption partners.

\section{Partner considerations}

If you are surprised by the complexity of the above mechanisms, you are probably not alone. Consumer and supplier behaviour is not necessarily logical. Just because it is rational to accrue and redeem points according to economic value, this does not mean these actions will be taken. Each partner may worry about being a net loser. Some partners may become net contributors of value back to customers (issuing more points value than subsequently spent with their brand), and others net beneficiaries (attracting more of the scheme's value to be spent with their business than they issue in points themselves).

Another motive for partners may be the desire to cut costs. Running one's own loyalty scheme is expensive: Tesco Clubcard is thought to cost over $£ 100 \mathrm{~m}$ to run each year. This is a lot, even for a large company. Safeway's ABC scheme reputedly became too expensive for a firm of Safeway's size to absorb. Nectar allows each partner to outsource a difficult and complex marketing operation. By sharing costs of customer acquisition, communications, data gathering and data analysis (so crucial to the success of Tesco Clubcard that they bought the expert firm DunnHumby), and by sharing the costs of managing each loyalty point the partners could save money. But it may be a mistake to suggest that you need to be the size of Tesco to run a loyalty scheme. The figure of $£ 100 \mathrm{~m}$ for Clubcard probably includes the cost of points — which are variable costs rather than fixed and can be absorbed within the customer margin. Boots, a firm of similar size to Safeway and much smaller than Tesco, has demonstrated how to run a successful scheme. Rather than cost savings, it may be that the main motives for partners of Nectar are the opportunities to sell to each others' customers and share information. People who shop with one partner but not with another partner, but who buy a lot of the latter's category, can be recruited for the latter. This is an 
Schemes are not easy to manage either

\section{Brand effects can be questionable}

advantage over Tesco - Tesco knows their own customers well but does not know so well those who are not their customers.

\section{After the honeymoon... The hard work begins Management challenges}

Partnership schemes have a mixed history. Firms such as Shell were never able to make their schemes work because of difficulties in persuading a major grocery firm to cooperate with a petrol retailer. AT\&T had similar problems with its Thanx scheme. There are also many management difficulties. Some partners may put in more effort than others. Disputes may arise over promotional affairs. Spur-of-the-moment decisions to run promotions are not possible because all parties must agree — the scheme must have rules. In short, keeping all the partners happy means more management costs that could cancel out economies of scale. So, proving that the schemes make net money is hard. Even solus schemes are partly an act of faith. Tesco is fond of its statistic that Clubcard customers spend twice as much as non-Clubcard customers. They imply that Clubcard delivers more spend, but the link may be the other way round - high spenders like Clubcard because their absolute discounts are higher.

\section{Consumer behaviour}

What do customers become loyal to? Nectar or Sainsbury's? Air Miles collectors like Air Miles, but not necessarily NatWest Bank. The danger for Nectar partners is that if one partner drops out of the programme and is replaced by another from the same category, consumers will drop the original partner. Any partner leaving would have to bear in mind that Nectar shares ownership of the data. While there is no suggestion that they may supply this to competitors, the issue of ownership remains. Finally, by entering a partnership scheme that has its own brand, partners distance themselves from the rewards in the minds of consumers. Tesco gets all the credit for Clubcard rewards, but to what extent does Sainsbury's 'take the credit' for its Nectar rewards? These brand problems are redoubled for other partners whose consumers purchase less often than Sainsbury's customers. The brand perception of the scheme is reinforced by the number of times customers have to present the card. But how often do consumers get their car serviced at a Ford garage? How often do they buy something in Argos?

\section{Customer insight is the key}

Are these schemes really about loyalty? Given the criticisms about points being low priority for customers in choosing brands, this is a fair question. Giving rewards for a purchase is an easily copied sales promotion, and most so-called 'loyalty' schemes are just that. So, for the partners these schemes are not about points, but about customer insight.

\section{Best practice at Tesco}

The best at this is Tesco, and worth a closer look. Tesco has delivered world-class retailing through better insights into their customers, adopting the principle 'we are what we eat'. Tesco analyses its customers to 


\section{Clustering is more than a myth}

measure their loyalty, their commitment to Tesco, their profitability and their 'headroom': the difference between what they spend at Tesco and how much they could potentially spend. Tesco has created a series of lifestyle clusters. The story of analysts of earlier schemes - indeed of check-out data - discovering lots of male shoppers with beer and nappies in the same basket bought on the way home from work is well known in the trade. The basket tells the story: harassed and tired fathers of young kids prioritising two essentials in their lives. As Humby et al. put it: "The beer-and-nappies correlation is the "what", the link to fatherhood is the "why", and an insight a retailer can work with. ${ }^{5}$ Analysts working on the Tesco scheme have discovered other clusters, eg those who like high-value pre-packaged foods; people who shop for basic ingredients and value foods; family convenience buyers, and so on. These were more useful than lifestage or recency/frequency/value approaches that had hitherto dominated. Tesco claims that re-running the new lifestyle clusters against old data showed the new segments to be three or four times more powerful than ones based on simple lifestage.

Some of Tesco's best work has been in using Clubcard data for price discount targeting. Price discounting is an essential and powerful tool in supermarket competition - but it is expensive. It takes a lot from the bottom line. Cutting the price of bananas is expensive - discounts are given to everyone, including many who are not bothered about price. Could Tesco avoid discounting to those who were not price sensitive? The hope was that Clubcard data could identify products that were signatures of people who shop exclusively on price. The data identified the perfect product - Tesco value brand margarine. It seems that Tesco used buying of Tesco value brand margarine as a surrogate for price-sensitive customers. They received higher discount offers to keep them at Tesco. The results were excellent. While Tesco's prices reduced by an average of 6 per cent across its entire range, its operating margins remained the same, boosted by superior loyalty among 'price-sensitives'.

Humby et al. also emphasise the importance of the names of the clusters for their marketing. ${ }^{6}$ While marketers often come up with names like 'young families', these do not have the power to evoke ideas in the same way as, say, 'high-spending superstore families' does. You can picture the latter better - it conveys an image that allows creative thinking to solve that family's problems.

Tesco is not the only successful creator of customer insight. Boots uses the data from its Advantage Card holders to support most customerrelated decisions it makes. These include product launches, direct marketing activity, promotions, store layout and the development of new services such as dentistry, health and beauty.

\section{Can Nectar achieve excellence in data mining and consumer insight?}

So, to what extent can partnership schemes acquire the customer insights that Tesco has successfully gleaned? Could they even do better, as their data extend across many more categories than grocery? For example, Nectar could perhaps identify a group: males who shop for family goods 
Does partnership weaken analysis?

\section{Is trust between partners a problem?}

in Sainsbury's late in the evening and who buy lots of fuel at BP. Let us call them 'busy male executives'. Maybe Debenhams could target these people with convenience-driven up-market gift offers at Christmas time. More simply, Nectar partners could identify and acknowledge their most valuable customers. One of this paper's contributors cites the use made by Total of their loyalty card database. His local outlet closed in October for rebuilding, and he received a personal letter in advance advising him of the temporary closure; apologising for any inconvenience caused; and forecasting when it would be likely to re-open. This is useful customer service. Whatever the exact form, using data for insights is regarded as a 'must' by many analysts. One contributor to this paper remarked that 'this is the number one benefit of a partnership scheme and the only way for a good ROI'.

This looks good on paper, but the Tesco story illustrates that getting there is not easy. Tesco analysts took years of trial and error to get the data flows and data mining right to allow these insights. It is very hard work. But at least Tesco was able to grapple with its data from close up. Can Nectar partners emulate their success when their data are held more remotely? This is a risky business. It puts the capabilities of exploiting Nectar's full potential out of the partners' direct control. There have been reports of some schemes' partners having to wait a long time for analysis of customer data: Tesco and Safeway, with their different outcomes, have illustrated the importance of getting this right. Nectar partners may want to copy Tesco's success in identifying 'price-sensitive' customers, and saving on margin through targeted discounts. But many of these 'pricesensitives' have that characteristic precisely because they have limited disposable income, in which case what will be the effect of several partners trying to stimulate more spend simultaneously through discount offers? There may well be some need for complex 'rules of engagement': but who would then be the doorkeeper?

\section{Using database marketing as a springboard for joint ventures}

The 'Holy Grail' of partnership schemes may be that having achieved a common view of the customer, and having unearthed new insights, the partners create joint ventures that offer complete solutions to customers - a kind of 'one-stop shop' that solves their problems in a joined-up way. Database marketing becomes clever enough to pin down who we are and what we want in a holistic way. Entire life events such as moving home, going on holiday or changing jobs could be catered for via one joint venture. The customer wins because they have the convenience of dealing with one trusted supplier. Could it be done? Experience suggests not quite yet, but some are optimistic. One of those who commented on an earlier draft of this paper remarked that a few years ago "the main two barriers to joint venture success were lack of computing power to manage the quantities of data and the unwillingness for companies to partner with others. Both no longer seem valid restrictions'. But other sources suggest that while Nectar's database does identify monetary value of individuals, it does not have the kind of capabilities for holding and analysing 


\section{Sharing gains equally}

transactional data that Tesco has leveraged. If so, if Tesco's experience is anything to go by, partners are a long way from emulating transactionbased insights. Without transaction data, partners are limited to basic cross-sell: deduplicate the Nectar data versus their own customer data and contact the remainder. This is not terribly sophisticated marketing and will not get high responses; but it is also lower-cost marketing - no DunnHumby-style analysis to worry about.

Of course joint ventures are also of concern to solus schemes. Tesco, for example, could use its extensive data from a partnership perspective in order to help fast-moving consumer goods manufacturers understand customers and their needs. Reputedly, one of the reasons Tesco bought into DunnHumby was to be able to share the data with its key suppliers. There are likely to be teething troubles even with these experienced executives. Should Tesco charge the suppliers for the data, or share it on the grounds of mutual gains from efficiency? Should category leaders get preferential access to data?

The worry for Nectar partners is whether, having given 1 per cent of their margin back to customers, they spend this elsewhere. One of the success factors for Nectar is undoubtedly balance - each partner must feel they are getting out of it what they put in. They must also feel that no one is being carried by the others. This kind of management is not easy: we are not talking about a well-oiled production process here.

Of course new technologies will open up new possibilities. One example is radio frequency identification (RFID) which will allow a card to communicate. Concerns about infringement of privacy have been raised about these 'spies in your wallet'. Here the debate has only just begun, and it is not clear whether such new technologies will benefit solus or partner schemes more.

\section{Conclusion: Drinking from the fireman's hose Early marketing success and strong partners}

Nectar partners know that making points schemes work is difficult. Consumers have felt that they have too many different 'bits of plastic', it takes too long to collect worthwhile rewards and redeeming points is often too complicated. So the marketing of the schemes has to be good. So far so good for Nectar. They have a catchy brand, and a powerful team of partners signed up. Their customer acquisition has succeeded where Shell Smart could not. Provided they can keep consumers reasonably happy, LMUK will have succeeded in creating a steady revenue stream for itself: its business model depends on lots of points swimming about. But the real game is going on backstage. An apparently successful scheme popular with consumers does not guarantee ultimate success: look at Safeway's ABC card, launched in 1995 and discontinued in 2000. The scheme cost $£ 60 \mathrm{~m}$ a year to run, but fell down because Safeway admits that it never properly used the data - collecting too much and being overwhelmed by it. In the final analysis, each partner is looking for the data gathered to give it that edge: small gains that come from a lot of hard work. Such small gains in sales, or smarter pricing, can generate considerable leverage. One analysis suggests that if Sainsbury's was able 


\section{It really is down to management}

to increase prices by 2 per cent on average its profits would increase by over 50 per cent.

\section{Will they manage the data and provide new opportunities?}

The lesson learnt from the different outcomes of Tesco and Safeway is the sheer hard work and management determination needed to manage all those data successfully. Managers working in any customer relationship management field with large companies will recognise this. Strategy is one thing; implementation quite another. If solus operations like Tesco or Safeway found coping with their data hard work, what does that say about the complexities of managing cross-sector data for multiple partners in different companies, different industries, with different requirements? This paper has barely scratched the surface of willingness to share, or legal issues. Some would find all that a frightening prospect. But the rewards may be worth the risk of investment. Joined-up data across categories allows joined-up thinking. It gives true insights into the lives of our consumers. Maybe Barclays, Sainsbury's, BP, Ford and Debenhams can put aside the management difficulties: Nectar could be the catalyst for the long awaited one-to-one tailored consumer solutions. An exciting and possibly threatening prospect!

\section{References}

1. Mitchell, A., Bauer, A. W. and Hausruckinger, G. (2003) The New Bottom Line: Bridging the Value Gaps that are Undermining your Business, Capstone Publishing, Oxford.

2. Ibid.

3. Kleinman, M. (2003) 'Nectar aims for long-term loyalty', Marketing, 18 September.

4. Gray, R. (2003) 'A relationship to recommend?', Marketing, 19 June.

5. Humby, C., Hunt, T. and Phillips, T. (2003) Scoring Points: How Tesco is Winning Customer Loyalty, Kogan Page, London.

6. Ibid.

\section{Further reading}

Ingall, J. (2003) 'Is it the end of the road for loyalty?', Admap, January, No. 435, p. 41.

Marketing (2003) 'Tesco Clubcard answers Nectar with Marriott tie' , 27 February, p. 12.

Stone M., Bearman, D., Butscher, S., Crick, P., Gilbert, D. and Moffett, T. (2003) 'The effect of retail customer loyalty schemes - Detailed measurement or transforming marketing?', Journal of Targeting, Analysis and Measurement for Marketing, Vol. 12, No. 3, pp. 305-318. 